\title{
A grading system from health to death using routine experimental indicators based on the pre-chronic disease status theory
}

\author{
Yang Guang, Li Yuzhong and Liu Hui
}

\begin{abstract}
Background: To establish a system for assessing pre-chronic disease status (PCDS) whereby changes in biomolecule levels occur before the appearance of physical damage to body organs. We based our study on the common biomarkers of aging, disease and end-of-life processes.

Methods: The red blood cell count as well as levels of albumin, creatinine and aspartate aminotransferase were used as indicators for measurement. The basic premise for determining PCDS was that the measured value was outside the reference range for a healthy individual. A binary outcome was determined according to reference range given by the laboratory undertaking the measurements. The Biological Age Index (BAl) was used to ascertain PCDS.
\end{abstract}

Results: The four indictors that we chose were sensitive for end-of-life and aging. The BAl score for each age group increased significantly with increasing age. The BAI score of patients with cardiac disease, cerebrovascular disease, cancer or chronic obstructive pulmonary disease were mostly higher than those in healthy age-matched people.

Conclusion: A system for assessing PCDS centered on biomolecular detection and independent of the pathologic diagnosis could be effective.

Keywords: Chronic disease, Risk assessment, Biological age, Biomarkers, Clinical chemistry

\section{Background}

In general, it is believed that chronic diseases have no specific virulence factors and are the result of a combination of various risk factors [1-3]. The "pre-chronic disease status" (PCDS) theory refers to changes in biomolecule levels before the appearance of physical damage to body organs (Fig. 1) [4]. The PCDS could be used to aid the early diagnosis of aging-related chronic diseases.

\footnotetext{
* Correspondence: liuhui60@sina.com

College of Medical Laboratory, Dalian Medical University, Dalian 116044, China
}

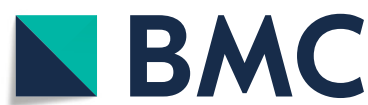

(c) The Author(s). 2020 Open Access This article is licensed under a Creative Commons Attribution 4.0 International License, which permits use, sharing, adaptation, distribution and reproduction in any medium or format, as long as you give appropriate credit to the original author(s) and the source, provide a link to the Creative Commons licence, and indicate if changes were made. The images or other third party material in this article are included in the article's Creative Commons licence, unless indicated otherwise in a credit line to the material. If material is not included in the article's Creative Commons licence and your intended use is not permitted by statutory regulation or exceeds the permitted use, you will need to obtain permission directly from the copyright holder. To view a copy of this licence, visit http://creativecommons.org/licenses/by/4.0/. The Creative Commons Public Domain Dedication waiver (http://creativecommons.org/publicdomain/zero/1.0/) applies to the data made available in this article, unless otherwise stated in a credit line to the data.

Finding the marker molecules of PCDS is very important. As stated above, chronic diseases are the result of multiple factors, so focusing on molecules considered to be the cause of chronic diseases (e.g., lipids) may not be the best strategy. Therefore, finding marker molecules that indicate decline in organ function or mild injury to organs may be a good approach.

Chronic disease is a continuous process, which is also a key issue in its early diagnosis. Because the theory of PCDS emphasizes the status of changes in biomolecule levels before the appearance of physical damage to body organs, changes in function at the 


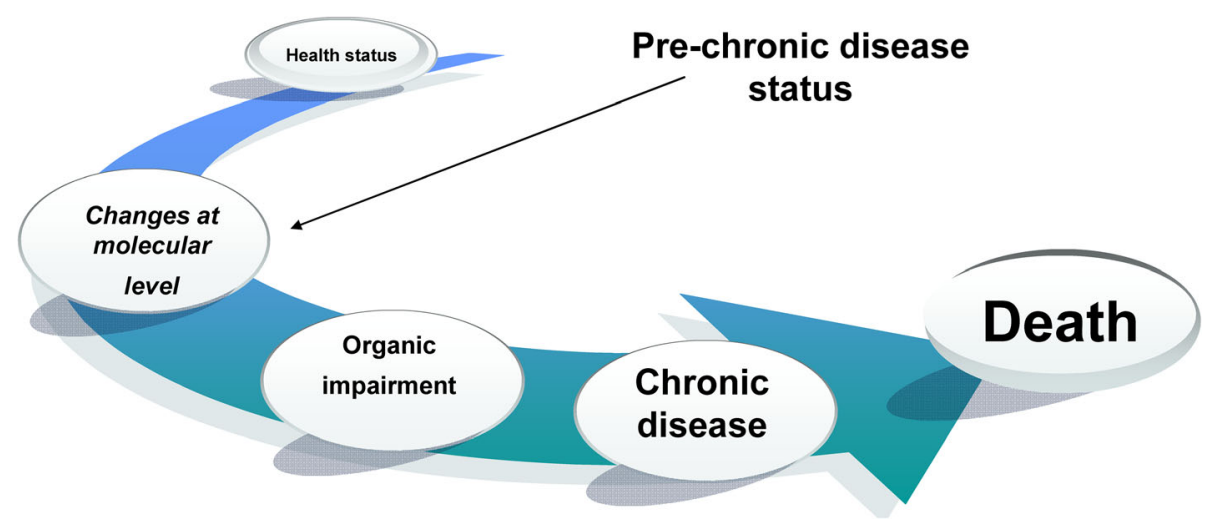

Fig. 1 Pre-chronic disease status (schematic)

molecular level are measured [4]. There are no pathologic changes in the PCDS, but there are changes in biomolecule levels. Therefore, the understanding of chronic diseases can be advanced from monitoring of tissues and organs to measuring changes at the molecular level [5-7]. Also, unlike pathologic alterations, changes in molecular levels are largely reversible, and reflect the clinical importance of the diagnosis of PCDS. Here, we used routine experimental indicators to construct a grading system from health to death. In this way, we studied chronic diseases from a new perspective.

\section{Methods}

\section{Study groups}

All patients were from the Second Affiliated Hospital of Dalian Medical University (Dalian, China). All procedures involving human participants were in accordance with the 1964 Helsinki Declaration (and its later amendments) or comparable ethical standards.

\section{Intensive care unit (ICU) group}

The sera of patients admitted to the ICU due to chronic diseases were collected. The sera of patients who died within 2 days ( 35 men and 23 women; age, $72.9 \pm 9.8$ years) and those who died at 20-30 days (25 men and 17 women; age, $71.8 \pm 10.3$ years) after ICU admission were retained for experimentation. The exclusion criteria for the ICU group were accidental injuries and no record of the time of death.

\section{Elderly group}

Sera were collected from individuals aged $>80$ years from the physical examination center (30 males and 30 females; age, $84.1 \pm 2.5$ years). The exclusion criteria were exacerbated episodes of various chronic diseases $\leq 4$ weeks before the study or long-term use of medication.

\section{Young group}

Sera were collected from individuals aged 20-30 years from the physical examination center (30 males and 30 females; age, $26.1 \pm 2.3$ years). Exclusion criteria were active infection or a history of hepatitis or other serious conditions.

\section{Physiologic-variation group}

Five volunteers ( 2 males and 3 females; age, 19-20 years) were selected and blood was collected twice at intervals of $24 \mathrm{~h}$.

Eighty-three volunteers (40 males and 43 females; age, $47.3 \pm 11.2$ years) were selected and blood was collected twice at intervals of 30 days.

\section{Verification group}

We obtained data from the medical records of the physical examination center. This group of 1950 volunteers (1032 males and 918 females) was aged 20-90 years. The inclusion criteria were patients: aged $>20$ years; who had visited the physical examination center for a routine health check-up rather than for specific medical treatment for ill-health; who did not have a history of taking medications on a long-term basis. The exclusion criteria were patients: with a chronic disease (e.g., coronary heart disease, cerebrovascular disease, chronic obstructive pulmonary disease (COPD), cancer); whose medical records did not have data on laboratory indicators. The active infection or a history of hepatitis or other serious conditions should also be excluded. 


\section{Disease group}

Data were obtained from the medical records of inpatients in the Second Affiliated Hospital of Dalian Medical University. Only preoperative and pretreatment data for these patients were used.

The coronary and cerebrovascular group comprised 165 patients (92 men and 73 women, $65.7 \pm 10.6$ years) with coronary heart disease (as evidenced by the findings of angiography and/or computed tomography (CT) of coronary vessels), cerebral thrombosis or cerebral hemorrhage (as evidenced by the findings of magnetic resonance imaging and/or $\mathrm{CT}$ ).

The COPD group was composed of 152 inpatients (48 men and 104 women, $68.0 \pm 13.8$ years). We included individuals diagnosed with COPD from stage II to IV according to Global Initiative for Chronic Obstructive Lung Disease criteria [8].

The cancer group comprised 324 cancer (gastric, liver or lung) patients (as evidenced by surgical intervention and/or pathologic findings) who underwent surgery (229 men and 95 women, $60.7 \pm 10.8$ years).

\section{Indicator selection}

According to previous works [9-12], we used five criteria to choose indicators: (i) the indicator responds to aging and end of life, and its response direction (increased or decreased) is consistent with the pathologic change in direction of the indicator. (ii) the physiologic and pathologic importance of the indicator is clear; (iii) the physiologic variation of the indicator is small; (iv) the indicator is employed widely and is easy to use; (v) assay of the indicator is inexpensive.

Using the criteria stated above, we chose four indicators: red blood cell (RBC) count as well as levels of albumin (ALB), creatinine (CRE) and aspartate aminotransferase (AST).

\section{Blood analyses}

Levels of AST (normal range: 15-40 U/L), CRE (men: 57-111 mol/L; women: 41-81 mol/L) and ALB (40-55

$\mathrm{g} / \mathrm{L})$ were measured using an automatic biochemistry analyzer (7170 s; Hitachi, Tokyo, Japan). RBCs (normal range, $4.30-5.80 \times 10^{12} / \mathrm{L}$ ) were counted using an automated hematology analyzer (SF-3000; Sysmex, Tokyo, Japan).

These investigations were carried out using standard commercial reagent kits in a clinical laboratory within Dalian Medical University. The coefficient of intra-assay variation was $<5 \%$ for each item assayed.

\section{Pre-disease status index (PDSI)}

The PDSI was calculated based on the Frailty Index [13]. The ratio of abnormality of the indicator is defined as the PDSI. Binary outcome should be converted according to the cut-off values given by the laboratory. For example, in a study participant with an abnormality in the AST level but not of other indicators, the sum was $0+0+0+1=1$. The PDSI was calculated from this sum as a percentage:

PDSI $=1 / 4=0.25$.

The greater the value of the PDSI, the higher the risk of a chronic disease.

\section{Laboratory health index (LHI)}

The mean value of the observation index (derived from the reference range of the level of an indicator given by the laboratory) was obtained. Based on the population mean of the indicator, it was divided into a healthy side and pathologic side. The ratio of the four indicators detected on the pathologic side was defined as "LHI", and the range was 0-1. For example, in a study participant with an ALB level that was within the range but over the healthy side of mean value; other three indicators were not, the sum was $0+1+0+0=1$. The LHI was calculated from this sum as a percentage:

$\mathrm{LHI}=1 / 4=0.25$.

The greater the value of the LHI, the lower the degree of health and the higher the risk of a chronic disease.

\section{Biological age index (BAI)}

We used the BAI to represent the process from health to death. Combining the PDSI and LHI, if the PDSI $>0$, the BAI was represented by PDSI +1 and, if the $\mathrm{PDSI}=0$, the BAI was represented by the LHI. The range of the $\mathrm{BAI}$ was 0 to 2 . Also, $\mathrm{BAI}>1$ indicated entry into PCDS.

\section{Statistical analyses}

The independent two-sample $t$-test (measurement data) and the chi-squared test (enumeration data) were used to assess differences among groups. Analyses were undertaken using SPSS v21 (IBM, Armonk, NY, USA). $P<0.05$ (two-tailed) was considered significant.

\section{Results}

The raw data of the test results are shown in Table 1. Levels of the four indicators showed significant differences between 2 days and 30 days before death and between the elderly and young groups. The direction of change of all indicators was consistent with the corresponding direction of pathologic change, which suggested that the four indicators could be used for PCDS assessment.

PDSI data are shown in Table 2. All participants had a PDSI $>0$ at 2 days before death. The probability of the PDSI being $>0$ was $8.3 \%$ in the youth group. The PDSI seemed to be slightly high for a youth 
Table 1 Original data for laboratory indicators in end-of-life patients and older and youth groups

\begin{tabular}{|c|c|c|c|c|c|c|c|c|c|}
\hline \multirow[t]{2}{*}{ Group } & \multirow[t]{2}{*}{$\mathrm{N}$} & \multicolumn{2}{|c|}{ Red blood cell } & \multicolumn{2}{|l|}{ Albumin } & \multicolumn{2}{|l|}{ Creatinine } & \multicolumn{2}{|c|}{ Aspartate aminotransferase } \\
\hline & & $\begin{array}{l}\text { P50 } \\
\text { (P25-P75) }\end{array}$ & $\begin{array}{l}\mathrm{P}+ \\
(\%)\end{array}$ & $\begin{array}{l}\mathrm{P} 50 \\
\text { (P25-P75) }\end{array}$ & $\begin{array}{l}\mathrm{P}+ \\
(\%)\end{array}$ & $\begin{array}{l}\text { P50 } \\
\text { (P25-P75) }\end{array}$ & $\begin{array}{l}\mathrm{P}+ \\
(\%)\end{array}$ & $\begin{array}{l}\text { P50 } \\
\text { (P25-P75) }\end{array}$ & $\begin{array}{l}\mathrm{P}+ \\
(\%)\end{array}$ \\
\hline $\begin{array}{l}\text { Death within } \\
2 \text { days }\end{array}$ & 58 & $\begin{array}{l}2.6 \\
(2.3-3.0)\end{array}$ & 93.3 & $\begin{array}{l}25.8 \\
(22.9-30.8)\end{array}$ & 98.3 & $\begin{array}{l}95.5 \\
(54.3-235.4)\end{array}$ & 55.2 & $\begin{array}{l}73.0 \\
(38.3-133.0)\end{array}$ & 74.6 \\
\hline $\begin{array}{l}\text { Death within } \\
20-40 \text { days }\end{array}$ & 42 & $\begin{array}{l}4.1 \\
(3.4-4.7)\end{array}$ & 59.5 & $\begin{array}{l}33.9 \\
(27.5-39.6)\end{array}$ & 84.6 & $\begin{array}{l}80.5 \\
(56.8-114.0)\end{array}$ & 45.2 & $\begin{array}{l}33.0 \\
(23.8-102.0)\end{array}$ & 43.6 \\
\hline $\begin{array}{l}\text { Age } \geq 80 \\
\text { years }\end{array}$ & 60 & $\begin{array}{l}4.6 \\
(4.3-4.9)\end{array}$ & 23.3 & $\begin{array}{l}43.5 \\
(42.0-45.0)\end{array}$ & 6.7 & $\begin{array}{l}72.0 \\
(63.0-88.5)\end{array}$ & 30.0 & $\begin{array}{l}22.5 \\
(19.0-27.8)\end{array}$ & 6.7 \\
\hline $\begin{array}{l}\text { Age 20-29 } \\
\text { years }\end{array}$ & 60 & $\begin{array}{l}4.9 \\
(4.6-5.2)\end{array}$ & 6.7 & $\begin{array}{l}47.6 \\
(46.4-48.6)\end{array}$ & 0 & $\begin{array}{l}61.5 \\
(50.5-76.0)\end{array}$ & 6.7 & $\begin{array}{l}18.0 \\
(16.0-24.0)\end{array}$ & 1.7 \\
\hline$P$ & & $<0.001$ & $<0.001$ & $<0.001$ & $<0.001$ & $<0.001$ & $<0.001$ & $<0.001$ & $<0.001$ \\
\hline
\end{tabular}

$\mathrm{P}+$ : Positive rate

group. However, it was acceptable because four indicators were used in our study, so the probability of either abnormal in four indicators should be $18.5 \%$ $\left(1-0.95^{4}\right)$.

BAI data for physiologic variation within 1 day and 1 month are shown in Table 3. About $50 \%$ of two test results were identical, $\sim 30 \%$ of the results belonged to fluctuation level 1 , and 5\% exceeded fluctuation level 2 (these were significant fluctuations, and suggested that health was getting better or worse).

BAI scores for each age group are shown in Table 4. The BAI score for each age group increased significantly with increasing age, indicating that the BAI model was effective. BAI scores for the gender group are shown in Table 5 . The BAI scores were similar between male and female groups, indicating that the BAI model was suitable for men and women. The observed population was not derived from building of the model, so the validity of the BAI could be verified.

BAI data for various diseases are shown in Table 6. The mean BAI score for each disease group was close to or $>1.0$. BAI scores in various diseases were mostly higher than those in the healthy group for the same age (Fig. 2). These data suggested, to a certain extent, that

Table 2 Pre-chronic disease status index in different groups

\begin{tabular}{lllllll}
\hline Group & $N$ & \multicolumn{6}{l}{ Pre-chronic disease status index } \\
\cline { 3 - 7 } & & 1.00 & 0.75 & 0.50 & 0.25 & 0 \\
\hline Death within & 58 & 22 & 26 & 10 & 0 & 0 \\
2 days & & $37.9 \%$ & $44.8 \%$ & $17.2 \%$ & & \\
Death within & 42 & 5 & 12 & 16 & 6 & 3 \\
20-40 days & & $11.9 \%$ & $28.6 \%$ & $38.1 \%$ & $14.3 \%$ & $7.1 \%$ \\
Age $\geq 80$ years & 60 & 0 & 2 & 12 & 10 & 36 \\
Age 20-29 & 60 & 0 & 0 & 4 & 1 & 55 \\
years & & & & $6.7 \%$ & $1.7 \%$ & $91.7 \%$ \\
$P$ & - & $<0.001$ & $<0.001$ & $<0.001$ & $<0.001$ & $<0.001$ \\
\hline
\end{tabular}

the BAI could be used to assess the risk of chronic diseases in healthy people.

\section{Discussion}

The PCDS theory conceptualizes an aging-related chronic disease as a continuous state. Our data for major lethal diseases (cardiovascular and cerebrovascular diseases, COPD and cancer) suggest that the initial stage and end stage of this continuous process were similar because of changes in levels of the four indicators (RBC count as well as levels of ALB, CRE and AST). We believe that the specific occurrence of a disease in the midst of this continuous process is the result of the cumulative effect of external factors and genetic factors, so the occurrence of specific diseases is random, and random damage will be manifested as multiple-organ damage.

The four indicators we selected were related to liver function, kidney function, hematopoiesis function and integrity of tissue, and the physiologic variations were small. Moreover, the four indicators were, theoretically, independent of each other. Once there is a simultaneous pathologic fluctuation, the disease risk is increased. Therefore, although the measured value did not lie outside the reference range, the fluctuation of multiple indicators simultaneously pointed to the direction of disease and could be considered to be the

Table 3 Physiologic variation for full health index within 1 day and 1 month

\begin{tabular}{lllllll}
\hline Result & $24 \mathrm{~h}$ & & \multicolumn{2}{c}{30 days } \\
\cline { 2 - 3 } & $\mathrm{N}$ & $\%$ & & $\mathrm{~N}$ & $\%$ \\
\hline Same & 3 & 60 & & 40 & 48.2 \\
Difference of one level & 2 & 40 & & 26 & 31.4 \\
Difference of two levels & 0 & 0 & & 11 & 13.3 \\
Difference over two levels & 0 & 0 & & 6 & 7.0 \\
Total & 5 & 100 & & 83 & 100 \\
\hline
\end{tabular}


Table 4 Biological age index and rate in different levels of health and pre-chronic disease in age groups

\begin{tabular}{|c|c|c|c|c|c|c|c|c|c|c|c|c|}
\hline \multirow[t]{2}{*}{ Age } & \multirow[t]{2}{*}{$\mathrm{N}$} & \multirow[t]{2}{*}{ Mean \pm SD } & \multicolumn{4}{|c|}{ Pre-chronic disease (\%) } & \multicolumn{5}{|c|}{ Health (\%) } & \multirow[t]{2}{*}{$P$} \\
\hline & & & 2.00 & 1.75 & 1.50 & 1.25 & 1 & 0.75 & 0.50 & 0.25 & 0 & \\
\hline 20- & 170 & $0.51 \pm 0.31$ & 0 & 0 & 2.4 & 5.3 & 0.6 & 18.2 & 41.2 & 25.9 & 6.5 & \\
\hline 30- & 328 & $0.61 \pm 0.31$ & 0 & 0 & 1.2 & 9.1 & 5.5 & 23.2 & 41.5 & 17.1 & 2.4 & \\
\hline 40- & 386 & $0.64 \pm 0.30$ & 0 & 0.3 & 1.6 & 8.5 & 3.9 & 30.1 & 40.9 & 13.5 & 1.3 & \\
\hline 50- & 295 & $0.70 \pm 0.35$ & 0 & 0 & 2.4 & 15.9 & 7.5 & 24.1 & 35.3 & 13.6 & 1.4 & $<0.001$ \\
\hline 60- & 117 & $0.70 \pm 0.33$ & 0 & 0 & 1.7 & 15.4 & 5.1 & 29.1 & 35.9 & 12.0 & 0.9 & \\
\hline 70- & 436 & $0.85 \pm 0.37$ & 0 & 0.7 & 5.5 & 26.6 & 6.9 & 27.1 & 26.4 & 6.7 & 0.2 & \\
\hline$\geq 80$ & 218 & $0.95 \pm 0.38$ & 0.5 & 1.8 & 12.8 & 23.4 & 12.4 & 27.1 & 17.9 & 4.1 & 0 & \\
\hline
\end{tabular}

risk of disease occurrence. This view was validated in different age groups. For example, in the 70-year-old group, most of the indicators were concentrated on the pathologic side of the mean value whereas, in the 30 -year-old group, most of the indicators were concentrated on the healthy side of the mean value.

Another concern was that some medications, such as antibiotics, may affect liver function [14-16] and kidney function $[17,18]$. Therefore, patients who take antibiotics and use medications long-term should be excluded. PCDS does not mean that a disease is already present, so a medication is not often used in PCDS. In practical terms, the influence of antibiotic use should be limited in our system.

Although the BAI does not denote a specific chronic disease, it can represent a biological age for an individual; aging brings with it increased risks for disease. We showed that the association between aging and disease was $>80 \%$ [19], so the experimental indicators related to aging (whether they be the cause or the result of the disease) could be used as an indicator for aging-related disease status. Results showed that the BAI score was higher in the disease group than that in the control group. However, the positive rate (instances when the BAI >1) was not $100 \%$. The explanation for this phenomenon is that diseases with typical changes have stopped. Hence, patients with the early stage of the disease or relatively healthy patients are observed in the surviving population, and it is necessary to observe them in the population before they die. At the end of the disease, the positive rate of the BAI was $100 \%$, which confirmed our interpretation to some extent. For the

Table 5 Biological age index in gender groups

\begin{tabular}{llllll}
\hline Group & N & Mean & SD & $t$ & $P$ \\
\hline Men & 1032 & 0.727 & 0.397 & 1.194 & 0.233 \\
Women & 918 & 0.707 & 0.313 & & \\
\hline
\end{tabular}

same reason, it is also necessary to further grade "health status" with BAI score.

PCDS theory states that changes in organ function from micro-injury may be compensated. We found that if a measured value was within the reference range, there remained a large influence in physiologic variation, and that this variation might also be the result of damage. However, if the measured value was within the reference range, we still considered it as a health status or an illhealth status rather than a PCDS. The basic factor for determining PCDS should be that the measured value was outside the reference range [20]. Hence, if someone was determined to have PCDS with a BAI $\geq 1-2$, the BAI could be targeted for interventions that may slow or prevent the chronic disease, or could be an indicator for evaluating clinical actions and intervention methods. This strategy could make medical professionals more aware of the repercussions of their medical decisions at the molecular level at the early stage of disease rather than at the stage of histopathologic impairments. An additional practical feature of our system was that it could provide a biomarker to evaluate the effectiveness of health administration objectively and promptly.

We emphasize employment of routine experimental indicators in our system for their generalizability. In all laboratories, close attention must be paid to the upper and lower limits of the reference range as well as the mean levels of the selected indicators, and adjustment for sex and ethnic groups must be made (if necessary). Therefore, our system could be generalized to other populations by adjusting the limits of the reference. Further investigation on the limits of the reference in different ethnic groups is needed to establish the appropriate system for a certain population.

\section{Conclusions}

PCDS theory emphasizes that changes at the molecular level are not limited to the pathologic changes observed in disease. Even if the pathologic changes have reached the criteria for the diagnosis of a disease, if the compensatory 
Table 6 Biological age index and rate at different levels of health and pre-chronic disease in major chronic disease groups

\begin{tabular}{|c|c|c|c|c|c|c|c|c|c|c|c|c|}
\hline \multirow[t]{2}{*}{ Disease } & \multirow[t]{2}{*}{ Age } & \multirow[t]{2}{*}{ N } & \multirow[t]{2}{*}{ Mean \pm SD } & \multicolumn{5}{|c|}{ Pre-chronic disease (\%) } & \multicolumn{4}{|c|}{ Health (\%) } \\
\hline & & & & 2.00 & 1.75 & 1.50 & 1.25 & 1.0 & 0.75 & 0.50 & 0.25 & 0 \\
\hline \multirow{4}{*}{$\begin{array}{l}\text { Coronary and } \\
\text { cerebrovascular disease }\end{array}$} & $<60$ & 46 & $1.13 \pm 0.41$ & 0 & 6.5 & 19.6 & 43.5 & 2.2 & 10.9 & 10.9 & 6.5 & 0 \\
\hline & $60-$ & 56 & $0.93 \pm 0.45$ & 0 & 7.1 & 5.4 & 37.5 & 0 & 8.9 & 33.9 & 7.1 & 0 \\
\hline & $70-$ & 46 & $1.15 \pm 0.37$ & 0 & 4.3 & 28.3 & 34.8 & 2.2 & 17.4 & 13.0 & 0 & 0 \\
\hline & $\geq 80$ & 17 & $1.38 \pm 0.40$ & 0 & 17.6 & 58.8 & 11.8 & 0 & 0 & 5.9 & 5.9 & 0 \\
\hline \multirow{5}{*}{$\begin{array}{l}\text { Chronic obstructive } \\
\text { pulmonary disease }\end{array}$} & $<50$ & 15 & $1.02 \pm 0.48$ & 0 & 0 & 20.0 & 46.7 & 0 & 6.7 & 6.7 & 20.0 & 0 \\
\hline & $50-$ & 34 & $0.91 \pm 0.43$ & 0 & 0 & 14.7 & 32.4 & 2.9 & 11.8 & 29.4 & 8.8 & 0 \\
\hline & $60-$ & 26 & $1.10 \pm 0.41$ & 0 & 0 & 30.8 & 34.6 & 3.8 & 7.7 & 19.2 & 3.8 & 0 \\
\hline & 70- & 40 & $1.06 \pm 0.42$ & 0 & 2.5 & 25.0 & 32.5 & 2.5 & 17.5 & 12.5 & 7.5 & 0 \\
\hline & $\geq 80$ & 37 & $1.34 \pm 0.36$ & 0 & 18.9 & 35.1 & 32.4 & 0 & 8.1 & 2.7 & 2.7 & 0 \\
\hline \multirow[t]{4}{*}{ Liver cancer } & $<50$ & 21 & $1.07 \pm 0.62$ & 0 & 23.8 & 19.0 & 19.0 & 0 & 4.8 & 9.5 & 19.0 & 4.8 \\
\hline & $50-$ & 32 & $1.30 \pm 0.42$ & 0 & 15.6 & 40.6 & 28.1 & 0 & 3.1 & 9.4 & 0 & 3.1 \\
\hline & $60-$ & 27 & $1.31 \pm 0.48$ & 0 & 33.3 & 25.9 & 18.5 & 0 & 3.7 & 14.8 & 3.7 & 0 \\
\hline & $\geq 70$ & 13 & $1.42 \pm 0.25$ & 0 & 15.4 & 53.8 & 23.1 & 0 & 7.7 & 0 & 0 & 0 \\
\hline \multirow[t]{3}{*}{ Lung cancer } & $<60$ & 43 & $0.87 \pm 0.50$ & 0 & 4.7 & 7 & 37.2 & 2.3 & 4.7 & 23.3 & 16.3 & 0 \\
\hline & $60-$ & 50 & $0.96 \pm 0.50$ & 0 & 6.0 & 14.0 & 36.0 & 0 & 6 & 26.0 & 8.0 & 0 \\
\hline & $\geq 70$ & 25 & $0.84 \pm 0.46$ & 0 & 0 & 20.0 & 20.0 & 0 & 4.0 & 48.0 & 8.0 & 0 \\
\hline \multirow[t]{3}{*}{ Gastric cancer } & $<60$ & 41 & $0.93 \pm 0.51$ & 0 & 2.4 & 22.0 & 29.3 & 0 & 2.4 & 26.8 & 14.6 & 2.4 \\
\hline & $60-$ & 41 & $1.00 \pm 0.46$ & 0 & 0 & 29.3 & 26.8 & 0 & 12.2 & 22.0 & 9.8 & 0 \\
\hline & $\geq 70$ & 31 & $1.31 \pm 0.37$ & 0 & 9.7 & 48.4 & 25.8 & 0 & 3.2 & 12.9 & 0 & 0 \\
\hline
\end{tabular}

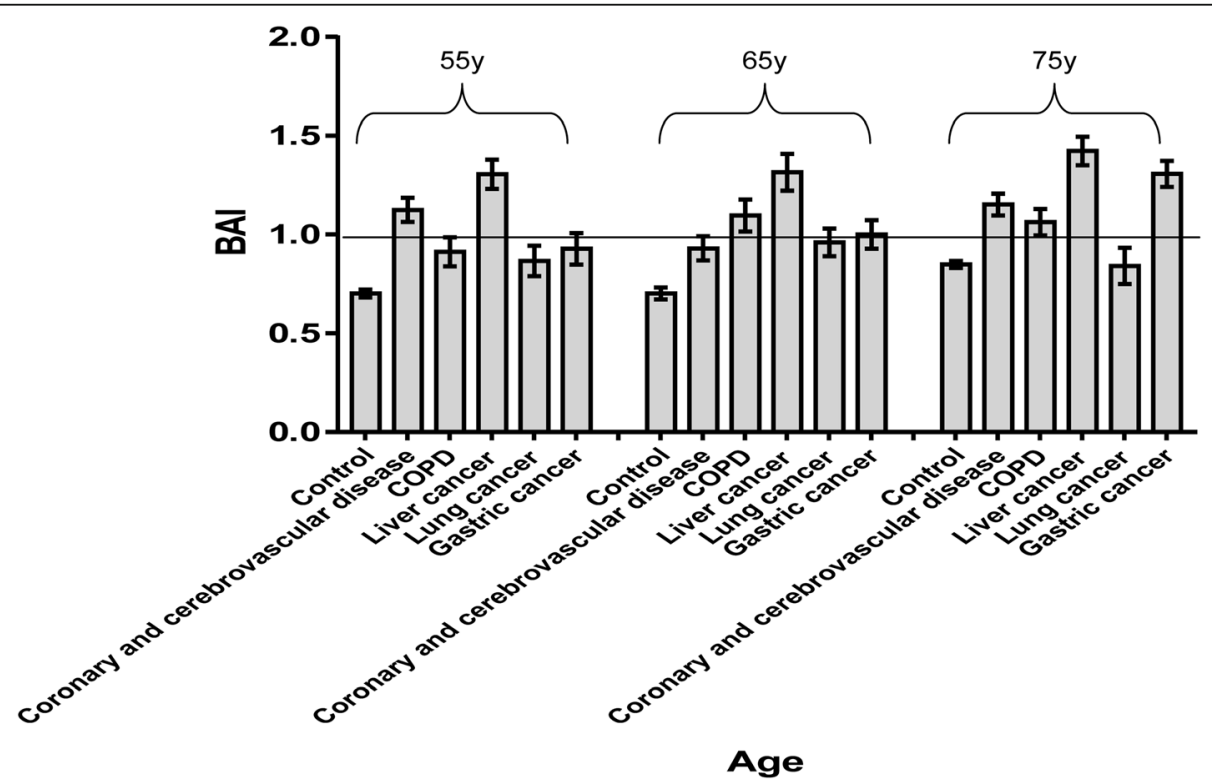

Fig. 2 The Biological Age Index (BAl) for various diseases in same age groupBAl scores in various diseases were mostly higher than those in the healthy group for the same age (although some diseases had a BAI < 1). 
function of an organ is strong, then body function can maintain a normal state, and there is no serious problem in PCDS theory. From this viewpoint, it is more meaningful to examine the function of the organ than to examine changes in the morphology of the organ. A system for assessing PCDS centered on biomolecular detection and independent of the pathologic diagnosis could be effective.

It is well known that test indicators with levels outside the reference range are considered "abnormal". Therefore, each laboratory should pay close attention to the upper or lower limits of the reference range and mean levels of indicators. This will become the basis of using PCDS theory into practice. In this way, it may be possible to develop a new field of laboratory-based medicine.

\section{Abbreviations}

ALB: Albumin; AST: Aspartate aminotransferase; BAI: Biological Age Index; CRE: Creatinine; COPD: Chronic obstructive pulmonary disease; ICU: Intensive care unit; LHI: Laboratory Health Index; PCDS: Pre-chronic disease status; RBC: Red blood cell

\section{Acknowledgments}

We thank Dong Feng, Cao Tinghui and Yu Lili for their help with data acquisition.

\section{Authors' contributions}

Y.G. performed the research and acquisition of data; L.Y. provided technical support; L.H. conceived the analysis and wrote the final version of the manuscript. All authors have read and approved the manuscript.

\section{Funding}

This work was supported by the National Natural Science Foundation of China [grant number 30770724], the Special Grant for Scientific and Technological Innovation of Dalian (2018J12SN084), and the Special Grant for Translational Medicine, Dalian Medical University [grant number No. 2015008]. The Foundation had no role in the design of the study and collection, analysis, interpretation of data or in writing the manuscript.

\section{Availability of data and materials}

The datasets used and analysed during the current study are available from the corresponding author on reasonable request.

\section{Ethics approval and consent to participate}

The Institutional Ethics Committee of Dalian Medical University approved the study and waived the need for written informed consent from the participants, as the samples were remnants following clinical use and therefore not specifically collected for this study and without risk to patients.

\section{Consent for publication}

Not applicable.

\section{Competing interests}

None declared.

Received: 4 July 2019 Accepted: 13 July 2020

Published online: 20 July 2020

\section{References}

1. Hui L. Quantifying the effects of aging and urbanization on major gastrointestinal diseases to guide preventative strategies. BMC Gastroenterol. 2018:673:107-11.

2. Qi $X, Y u Y$, Ji N, Ren $S, X u Y$, Liu H. Genetic risk analysis for an individual according to the theory of programmed onset, illustrated by lung and liver cancers. Gene. 2018;673:107-11.

3. Hui L. Chronic diseases and societal development. Based on the Death-risk Index Epidemiology. 2015;26(1):e9-e10.
4. Wenping S, Ying L, Song L, Yuzhong L, Hui L. Objective assessment of health or pre-chronic disease state based on a health test index derived from routinely measured clinical laboratory parameters. J Transl Med. 2015;13:127.

5. Hui L, Rixv L, Xiuying Z. A system for tumor heterogeneity evaluation and diagnosis based on tumor markers measured routinely in the laboratory. Clin Biochem. 2015;48:1241-5.

6. Hongwei W, Hui L. Quantitatively plotting the human face for multivariate data visualization illustrated by health assessments using laboratory parameters. Comput Math Methods Med. 2013;2013:390212.

7. Guang Y, Jie Z, Feng D, Hui L. Surrogate scale for evaluating respiratory function based on complete blood count parameters. I Clin Lab Anal. 2018; 32(5):e22385.

8. Cao T, Xu N, Wang Z, Liu H. Effects of glutathione S-Transferase gene polymorphisms and antioxidant capacity per unit albumin on the pathogenesis of chronic obstructive pulmonary disease. Oxidative Med Cell Longev. 2017;2017:6232397.

9. Hui L, Wang G-g, Zhiyue L, Yanan G. Association analysis of biological variations in different routinely measured biochemical parameters in healthy subjects. Labmedicine. 2009;40(8):474-7.

10. Hongwei W, Xinyu Z, Guihong L, Xiliang L, Hui L. Nonspecific biochemical changes under different health statuses and a quantitative model based on biological markers to evaluate systemic function in humans. Clin Lab. 2010; 56:223-5.

11. Chongliang F, Yuzhong L, Qian S, Xiliang L, Hui L. Development of a prognostic score using the complete blood cell count for survival prediction in unselected critically ill patients. Biomed Res Int. 2013;2013:105319.

12. Hui L, Qigui L, Sashuang R, Xiliang L, Guihong L. Nonspecific changes in clinical laboratory indicators in unselected terminally ill patients and a model to predict survival time based on a prospective observational study. J Transl Med. 2014;12:78.

13. Wang C, Liu C, Gao H, Liu H. Order of aging of major human organs or systems and evaluation of health status based on aging. Biomarkers. 2017; 22(2): $145-8$

14. Björnsson ES. Drug-induced liver injury due to antibiotics. Scand J Gastroenterol. 2017;52(6-7):617-23.

15. Munz M, Grummich H, Birkmann J, Wilhelm M, Holzgrabe U, Sörgel F. Severe drug-induced liver injury as an adverse drug event of antibiotics: a case report and review of the literature. Chemotherapy. 2017;62(6):367-73.

16. Udo R, Tcherny-Lessenot S, Brauer R, Dolin P, Irvine D, Wang Y, Auclert L, Juhaeri J, Kurz X, Abenhaim L, Grimaldi L, De Bruin ML. The risk of acute liver injury associated with the use of antibiotics-evaluating robustness of results in the pharmacoepidemiological research on outcomes of therapeutics by a European consortium (PROTECT) project. Pharmacoepidemiol Drug Saf. 2016;25(Suppl 1):47-55.

17. Al-Dorzi HM, Eissa AT, Khan RM, Harbi SAA, Aldabbagh T, Arabi YM. Dosing errors of empirical antibiotics in critically ill patients with severe sepsis or septic shock: a prospective observational study. Int J Health Sci (Qassim). 2019;13(4):48-55.

18. Hobbs AL, Shea KM, Roberts KM, Daley MJ. Implications of augmented renal clearance on drug dosing in critically ill patients: a focus on antibiotics. Pharmacotherapy. 2015;35(11):1063-75.

19. Hui L. Assessment of the role of ageing and non-ageing factors in death from non-communicable diseases based on a cumulative frequency model. Sci Rep. 2017;7(1):8159.

20. Wenping S, Ying L, Yuzhong L, Hui L. Variations in laboratory parameters in prechronic disease to determine disease occurrence at the molecular level. Biomark Med. 2019;13(14):1227-34.

\section{Publisher's Note}

Springer Nature remains neutral with regard to jurisdictional claims in published maps and institutional affiliations. 